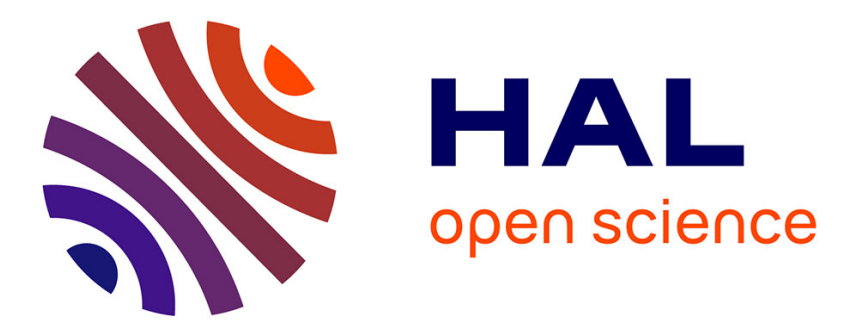

\title{
A new multiaxial specimen for determining dynamic properties of adhesive joints
}

A. Janin, Andrei Constantinescu, Daniel Weisz-Patrault, R. Neviere, M. Stackler, W. Albouy

\section{- To cite this version:}

A. Janin, Andrei Constantinescu, Daniel Weisz-Patrault, R. Neviere, M. Stackler, et al.. A new multiaxial specimen for determining dynamic properties of adhesive joints. Experimental Mechanics, 2018, 10.1007/s11340-018-0402-7 . hal-01823192

\section{HAL Id: hal-01823192 \\ https://hal.science/hal-01823192}

Submitted on 25 Jun 2018

HAL is a multi-disciplinary open access archive for the deposit and dissemination of scientific research documents, whether they are published or not. The documents may come from teaching and research institutions in France or abroad, or from public or private research centers.
L'archive ouverte pluridisciplinaire HAL, est destinée au dépôt et à la diffusion de documents scientifiques de niveau recherche, publiés ou non, émanant des établissements d'enseignement et de recherche français ou étrangers, des laboratoires publics ou privés. 


\title{
A new multiaxial specimen for determining dynamic properties of adhesive joints
}

\author{
A. Janin · A. Constantinescu - D. Weisz-Patrault · R. \\ Neviere · M. Stackler · W. Albouy
}

Received: date / Accepted: date

\begin{abstract}
Adhesive joints are increasingly introduced in industrial structures for bonding critical parts. Their mechanical characterization is a key element for design and is, therefore, necessary. A significant work has been done for the characterization under quasi-static conditions, but techniques are rather limited for dynamic conditions. Indeed, existing dynamic studies characterize adhesive assemblies and not the adhesive joint alone, and do not investigate multiaxial loadings. Thus, this paper proposes an innovative experimental technique for the characterization of adhesive joints under dynamic multiaxial loadings. The experimental method relies on three main components: i) a conventional Split Hopkinson Pressure Bar (SHPB) apparatus, ii) a novel specimen named as DODECA enabling to test three distinct multiaxial loadings with the same methodology and iii) local strain and stress measurements performed by Digital Image Correlation (DIC). The paper exhibits all steps of the experimental procedure as well as underlying preparation and measuring methods. Stress and strain in the adhesive joint are estimated from experimental data directly both during loading and at the failure point. Finally, the dynamic material behavior of the adhesive joint is identified from the data.
\end{abstract}

Keywords Adhesive joints $\cdot$ DODECA specimen · Dynamic loading · Digital image correlation

\section{Introduction}

Within the framework of energy efficiency and structure lighting, especially for aeronautical applications, the assembly of composite elements using adhesive joints emerged as an interesting alternative to conventional methods such as riveting or screwing. However, adhesive joints are not sufficiently understood and characterized to obtain certifications for critical structural assemblies. Therefore, it is necessary to have a detailed knowledge of the adhesive joint behavior in order to model assemblies of industrial parts. Moreover, these bonded joints are subjected to wide ranges of loading conditions: quasi-static and dynamic multiaxial loadings, thermomechanical fatigue or aging. The present work focuses on the experimental characterization of adhesive joints under dynamic multiaxial loadings. Significant efforts have already been made for quasi-static loadings $[1,2]$. However, the existing studies dealing with dynamic loadings rely on the single-lap joint specimen [3] or the double-lap joint specimen $[4,5]$ which only investigate the shear behavior of adhesive joints. Thus, the applicability for more complex loading conditions is still limited. Another argument in favor of testing under multiaxial loading is the stress dependence of the mechanical behavior of polymers, like the yield strength, as described for example in [6]. In addition,

\author{
A. Janin \\ LMS, École Polytechnique, Université Paris-Saclay, \\ Palaiseau, France \\ Safran Composites, \\ Itteville, France \\ E-mail: anthony.janin@polytechnique.edu \\ A. Constantinescu · D. Weisz-Patrault \\ LMS, École Polytechnique, CNRS, Université Paris-Saclay, \\ Palaiseau, France \\ E-mail: andrei.constantinescu@ polytechnique.edu \\ R. Neviere · M. Stackler · W. Albouy \\ Safran Composites, \\ Itteville, France
}




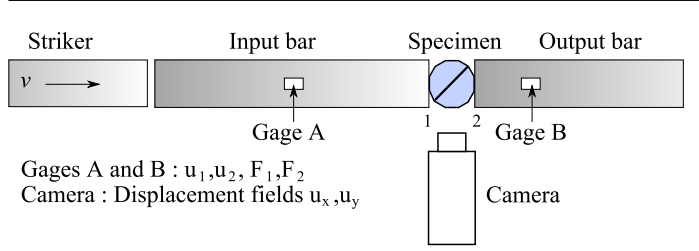

Fig. 1 Experimental set-up scheme of the SHPB apparatus and the local optical measurement system

dynamic adhesive joints tests are usually performed with Hopkinson bar systems that provide only global measurements: displacements and resultant forces at both ends of the specimen. This characterizes the adhesive assembly, but not of the adhesive joint [3-5]. Therefore, an additional local measurement system during the dynamic testing is of great interest.

The goal of this paper is to characterize the dynamic behavior of adhesive joints using SHPB system and to overcome the two difficulties:

1) by proposing an experimental setup adapted to different multiaxial loading conditions.

2) by adding a local measurement system with high spatial and temporal resolutions to provide relevant information about the adhesive joint.

The first difficulty is to create multiaxial loading conditions. They can be achieved by torsional [7] or tensile [8] Hopkinson bar systems. However, each experimental apparatus provides only one stress state, and explore several stress states seems difficult. Another option is to perform classic compressive dynamic tests using conventional SHPB systems and to design specific specimen geometries in order to obtain multiaxial stress states depending only on a structural effect. Different specimen geometries have been proposed for homogeneous materials (i.e., without adhesive joint) and optimized for a well-defined stress state. For instance, the Compact Compression Specimen (CCS) [9] is designed to study dynamic fracture with large traction component and low shear stress at the crack tip. The main advantage of this specimen geometry is to necessitate only a conventional compression Hopkinson bar system although significant traction is produced. The Shear Compression Specimen (SCS) [10] is dedicated to the characterization of $2 \mathrm{~mm}$ thick polymer films under a biaxial stress state of compression and shear. The Shear Tension Specimen (STS) [11] is designed to characterize metals under a biaxial stress state of tension and shear. The Double Edge Notched Compression Specimen (DENCS) [12] has been used for measuring compressive fracture toughness in dynamic tests. In addition, the well-known Brazilian Disk (BD) specimen has been widely used for the identification of material toughness within the framework of dynamic tests $[13,14]$. Some authors proposed an interesting attempt to adapt the original BD specimen to bonded assemblies in quasi-static regime $[15,16]$ with the Sandwich Brazilian Disk (SBD) specimen design. This specimen offers an infinite number of stress states by varying the impact angle in the Hopkinson bar system. In this contribution, a new specimen inspired from the SBD is proposed for dynamic multiaxial loading conditions. It changes the SBD disk into a dodecagon to assure flat surfaces and a plane-to-plane contact between bars and the specimen to ease experimental and numerical procedures. The obtained specimen is then a sandwich dodecahedron called the DODECA specimen. This geometry has already been presented [17]. In the present contribution, a new version is proposed in order to avoid edge effects and regularize stresses at both ends of the joint. A specific shape has been designed for this purpose. The specimen geometry enables three different impact angles leading to three different stress states in the adhesive joint.

The second difficulty is the coupling of a local measurement system with the global measurement system of the dynamic loading. In dynamic testing, several options are available : Moir interferometry [18], crack growth photography [19], Digital Image Correlation (DIC). The DIC method has proved its potential in quasi-static measurements [20,21], and dynamic measurements [8, 22-24] in recent years. This transition has been possible thanks to technological advances in high-speed imaging systems. In this work, a high-speed camera has been used in order to measure local displacements by DIC. Due to technological limitations, a compromise has to be done between acquisition frequency and spatial resolution. To get optimal measurements, a particular attention has been given to speckle pattern techniques [25]. Micrometric resolution has been obtained in the present work.

The paper is organized as follows. The SHPB system is briefly recalled in section 1 . Then, the innovative DODECA specimen is presented in section 2 . The local measurement setup in the adhesive joint is detailed in section 3. Finally, results are presented and discussed in section 4. 


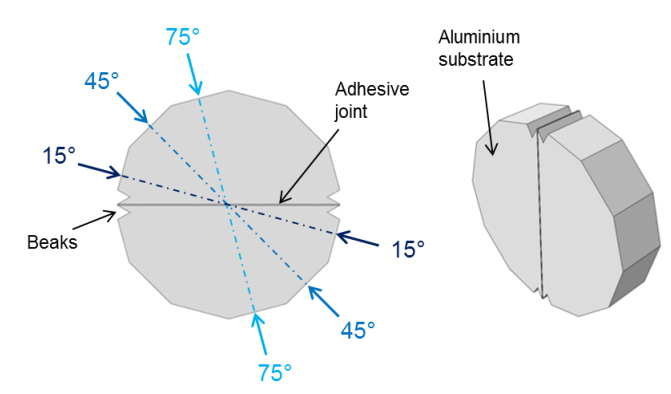

Fig. 2 Schematic view of the DODECA specimen

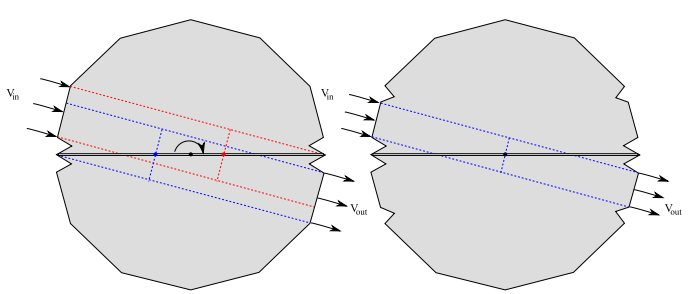

Fig. 3 Geometrical adjustments to avoid rotation for the $15^{\circ}$ condition

\section{Dynamic testing}

The dynamic testing is done using the SHPB apparatus and traditional analysis methods. For a detailed review of this method, the reader is referred to [26-29]. The conventional configuration of the Hopkinson bar system is made of two $40 \mathrm{~mm}$-diameter high strength aluminum bars. The $86-120 \mathrm{~cm}$-long striker bars are made of the same material and have the same diameter as both input and output bars. The output bar is $2 \mathrm{~m}$ long, and the input bar is $3 \mathrm{~m}$ long in order to allow longer loading duration. The DODECA specimen is placed between the two bars as shown in Fig. 1. Displacements and forces at bars/specimen interfaces are determined from strain measurements recorded at input and output gauge stations with $1 \mathrm{MHz}$ acquisition frequency. The post-processing of strain signals was done with DAVID software [30] which includes noise filtering, checking force and energy balances, elastic simulation for an accurate transport of elastic waves to interfaces, wave dispersion and local punching correction [31]. This Hopkinson bar configuration was used for striker impact velocities between 5 and $15 \mathrm{~m} / \mathrm{s}$ measured with a laser. Silicon grease is applied between the specimen and the bars in order to avoid shear contact stress. In addition, a $50 \mu \mathrm{m}$-thick pulse shaper is fixed on the input bar. This technique produces a more constant strain rate by limiting sharp strain rates at the beginning of the test. Thus, repeatability is improved.

\section{DODECA specimen}

\section{Geometry}

In this section, the DODECA specimen is presented. It consists in a sandwich-dodecahedron (dodecahedron cut in two parts by the adhesive joint) which can be inscribed in a $40 \mathrm{~mm}$ diameter disk. The proposed specimen is made of $10 \mathrm{~mm}$-thick aluminum bonded by a $300 \mu \mathrm{m}$-thick adhesive joint. A previous design has been proposed in [17]. However, the design leaded to edge effects in the adhesive joint. This is a known phenomenon in the field of adhesive joints characterization [1,2]. The present version has been improved by introducing beaks near both edges of the joint as shown in Fig. 2, in order to regularize the stress field in these zones. Three impact angles are defined and labeled $15^{\circ} 45^{\circ}$ and $75^{\circ}$. This geometry is well suited for $45^{\circ}$ and $75^{\circ}$ conditions. However, the $15^{\circ}$ condition needs an adjustment. Beaks reduce the contact surface between the specimen and the Hopkinson bars. Contact surfaces are not aligned with the mass center of the specimen which leads to a torque as shown on the left part of Fig. 3. This torque causes specimen rotation from the beginning of the impact loading. A simple solution consists in reducing contact surfaces in order to restore the alignment of contact pressure with the mass center of the specimen as shown on the right part of Fig. 3.

Furthermore, as shown in section Numerical simulation, the stress state for $75^{\circ}$ loading condition is highly compressive and joint failure can be difficult. Therefore, if failure is studied, samples dedicated to this loading condition are not bonded all along the specimen length, but only on $12 \mathrm{~mm}$ at the center. 

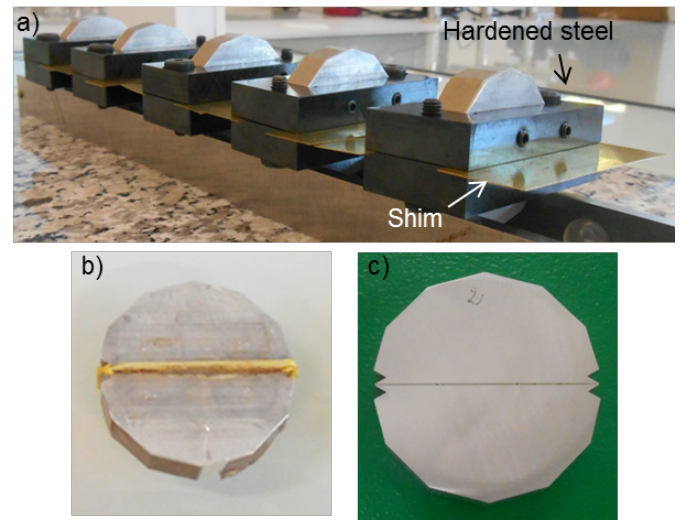

Fig. 4 a) Specimens before curing and bonding devices. b) Specimen just after curing. c) Final specimen ready to be tested

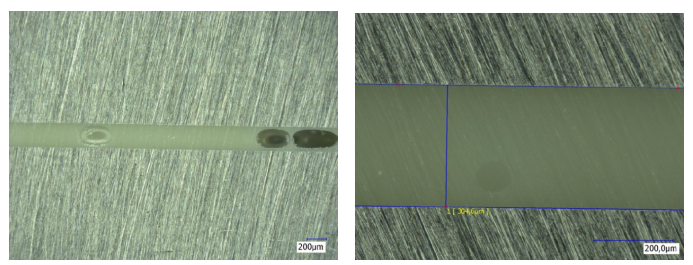

Fig. 5 Digital microscopy of the adhesive joint : view of defaults in the adhesive joint and measurement of adhesive thickness

\section{Fabrication}

The DODECA specimen is made by gluing the two aluminum parts with the adhesive joint. In order to control the thickness of the joint, a special manufacturing device has been conceived. The bonding device is presented in Fig. 4. The initial bonding device presented in [17] has changed to improve accuracy and homogeneity of the adhesive thickness all along the specimen. Five samples can be prepared at the same time. Two lateral screws apply pressure on two faces of the dodecahedron in order to maintain adherents in the jig. Two vertical centering screws are used to apply pressure on specimens in the normal direction of the adhesive joint during the whole curing process. Satisfying alignment of both adherents is ensured. The joint thickness is controlled by introducing $300 \mu \mathrm{m}$-thick shims shown in Fig. 4. The bonding procedure is summarized as follows:

1) Release agent is applied with a brush on the shims and inside the jig where there is contact between the jig and the adherent. Then, they are left 10 minutes under a hood for drying.

2) Adherents are mounted in the jig and the bottom parts should be proud of $200 \mu \mathrm{m}$ above the reference flat surface of the jig. If this value is not reached due to machining tolerances, Teflon adhesive tape is applied underneath in order to raise the lower adherent to the nominal value.

3) Lateral screws are tightened in order to avoid slips during the curing process.

4) Surfaces to be bonded are still proud of $200 \mu \mathrm{m}$. Thus, they are ground till the reference level of the jig with a P600 carbide sand paper.

5) Surfaces are roughly washed with water, then washed three times with isopropanol and left to dry for 10 minutes under a hood.

6) Release agent is applied on remaining surfaces that should not be bonded.

7) The adhesive joint is a thin film that is cut into $10 \times 39 \mathrm{~mm}$ pieces with a sharp knife. The film is then applied on one surface to be bonded.

8) Vertical screws are tightened until shims are blocked.

9) The joint is cured at $150^{\circ} \mathrm{C}$ during 3 hours, and the excess of glue is cut off at the end of the curing process.

10) Lateral faces are polished in order to facilitate the Digital Image Correlation.

The adhesive bond quality is estimated by digital microscopy as shown in Fig. 5. The obtained samples present few air bubbles (5\% of the lateral surface). The average joint thickness is $300 \mu \mathrm{m}$ with $6 \%$ variations along the joint length. 


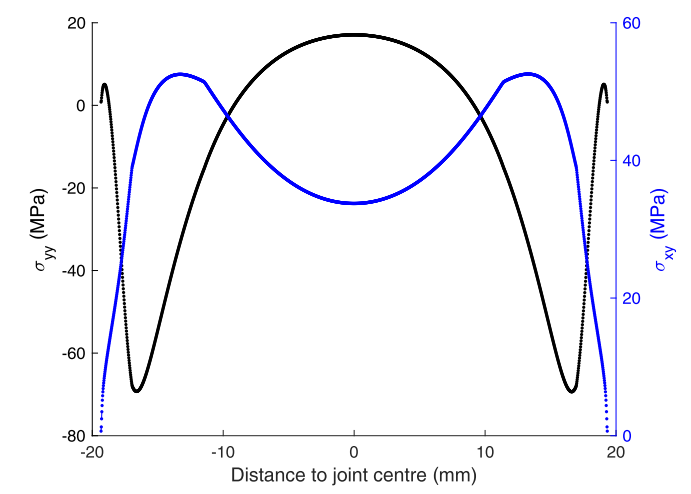

Fig. 6 Numerical simulation: normal stress $\sigma_{y y}$ (black line) and shear stress $\sigma_{x y}$ (blue line) versus the distance to the joint centre for the $15^{\circ}$ loading condition

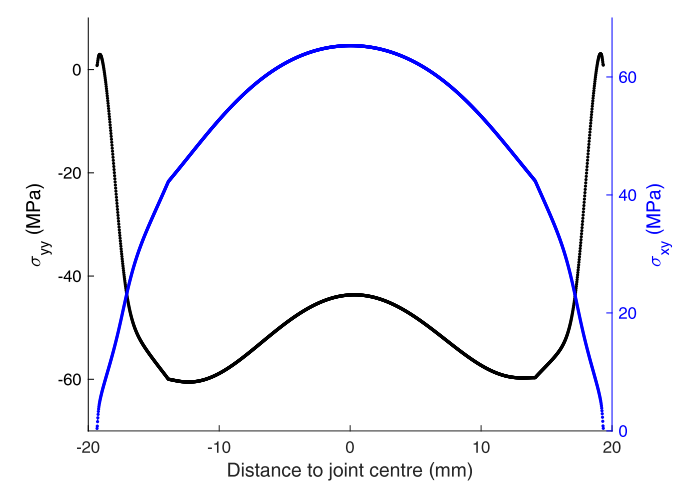

Fig. 7 Numerical simulation: normal stress $\sigma_{y y}$ (black line) and shear stress $\sigma_{x y}$ (blue line) versus the distance to the joint centre for the $45^{\circ}$ loading condition

\section{Numerical simulation}

Numerical simulations have been performed in order to design the DODECA specimen. An elastic Finite Element analysis has been performed with the software ABAQUS [32]. Stress distribution along the adhesive joint is evaluated as a function of time for $15^{\circ}, 45^{\circ}$ and $75^{\circ}$ loading conditions. Practically, two-dimensional quasi-static simulations have been performed in order to avoid a very long computation time. A very simplified Hopkinson bar impact is modeled by imposing displacements of $100 \mu \mathrm{m}$ along the normal direction of input specimen surface and by blocking displacements at the output surface. 80000 4-node reduced integration elements (CPS4R) are used with elastoplastic properties of both adhesive joint and substrate. There are 10 elements in the thickness of the adhesive joint, in order to analyze interface and bulk stresses. The aim is not to reproduce a Hopkinson bar experiment accurately, but to find the stress distribution in the joint with a typical loading condition in terms of amplitude. More representative models $[4,10]$ could be used to analyze the stress distribution in this experiment, but, they would have a significant calculation time. Results are presented in Fig.6, 7 and 8. It should be noted that $x$ and $y$ denote the joint length and the joint thickness directions respectively. All stress distributions are heterogeneous but show a critical stress state in the joint centre, with joint edges unloaded. Tab. 1 summarizes the three stress distributions according to the loading angle with the DODECA specimen.

Moreover, as mentioned in section Geometry, the proposed geometry presents beaks at joint edges in order to avoid stress singularities. The effect of this specific geometrical adjustment is presented in Fig. 9 and 10. Adding beaks does not change stress distribution, but eliminate edge effects as expected. Indeed, analytical approaches have proved that substrates with beaks (substrate angle $\leq 50^{\circ}$ ) reduce stress singularities [33, 34].

\section{Digital Image Correlation}

A local displacement measurement method is considered with Digital Image Correlation (DIC). Since the test duration is about a few hundreds of $\mu$ s, a high-speed imaging system is needed. The temporal 


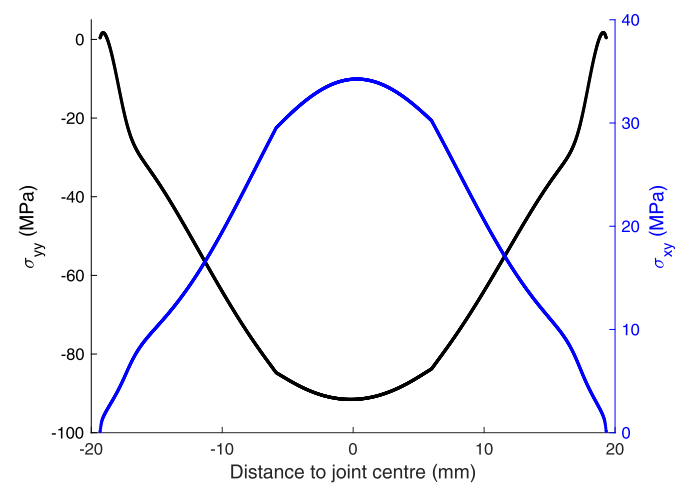

Fig. 8 Numerical simulation: normal stress $\sigma_{y y}$ (black line) and shear stress $\sigma_{x y}$ (blue line) versus the distance to the joint centre for the $75^{\circ}$ loading condition

Table 1 Summary of available stress distributions with the DODECA specimen

\begin{tabular}{llll}
\hline $\begin{array}{l}\text { Loading } \\
\text { angle }\left(^{\circ}\right)\end{array}$ & Shear & Compression & Tension \\
\hline 15 & ++ & no & + \\
45 & ++ & + & no \\
75 & + & ++ & no \\
\hline
\end{tabular}

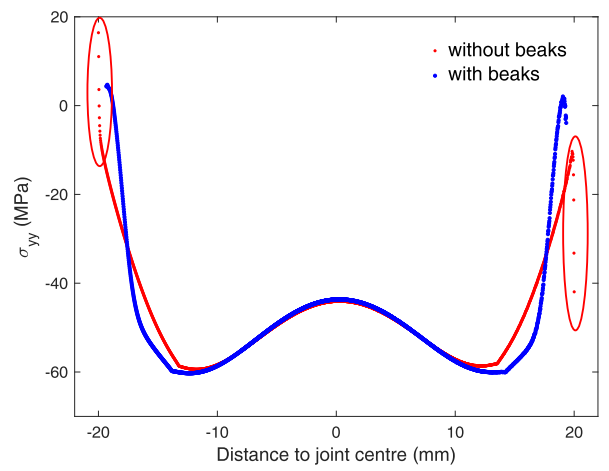

Fig. 9 Numerical simulation : normal stress $\sigma_{y y}$ as a function of distance to joint centre, with and without beaks

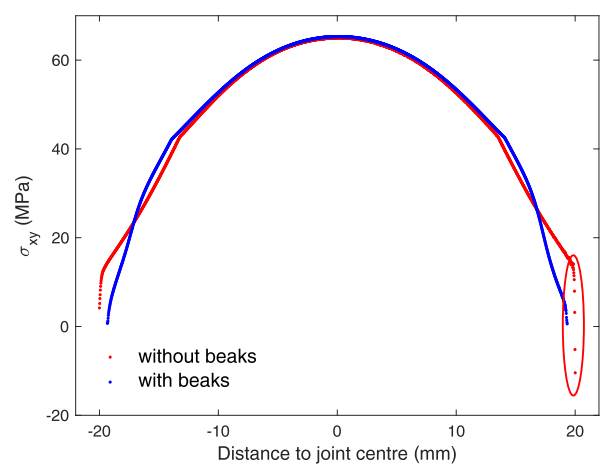

Fig. 10 Numerical simulation : shear stress $\sigma_{x y}$ as a function of distance to joint centre, with and without beaks

resolution should be at least 70,000 frames per second (fps). Thus, in dynamics, there is a compromise to be made between spatial resolution and acquisition frequency. Typical quasi-static studies use very high spatial resolution (for instance, $2048 \times 2048$ pixels) pictures to do DIC. In dynamics, this standard cannot be reached because of the very high temporal resolution needed. To get high-quality DIC measurements with a low spatial resolution, images contrast has to be optimal. Thus, a particular attention has been given to lightning techniques and speckle pattern. A very powerful lightning is required on the area of interest because of the low exposure time. In this contribution, a halogen flashlight (triggered with the input strain gauge) is used to overcome this issue. Furthermore, a speckle pattern is applied with an airbrush on the 
Table 2 High-speed imaging parameters

\begin{tabular}{|c|c|}
\hline Camera & Phantom v7.3 \\
\hline Lighting & $\begin{array}{l}\text { Visatec SOLO } 1600 \text { B } \\
\text { (halogen flashlight, } 150 \\
\text { W) }\end{array}$ \\
\hline Lens & Nikon 105 mm f $2.81: 1$ \\
\hline Exposure time & $1 \mu \mathrm{m}$ \\
\hline Time between 2 images & $13-14 \mu \mathrm{s}$ \\
\hline Resolution $15^{\circ}$ and $45^{\circ}$ & $\begin{array}{l}416 \times 80 \text { pixels }(1 \mathrm{px} \simeq 52 \\
\mu \mathrm{m})\end{array}$ \\
\hline Resolution $75^{\circ}$ & $\begin{array}{l}196 \times 144 \text { pixels }(1 \mathrm{px} \simeq 55 \\
\mu \mathrm{m})\end{array}$ \\
\hline Software DIC & Vic2D \\
\hline Subset displacements & 9 pixels (step : $1 \mathrm{px}$ ) \\
\hline Subset strains & 21 pixels (step : $1 \mathrm{px}$ ) \\
\hline
\end{tabular}
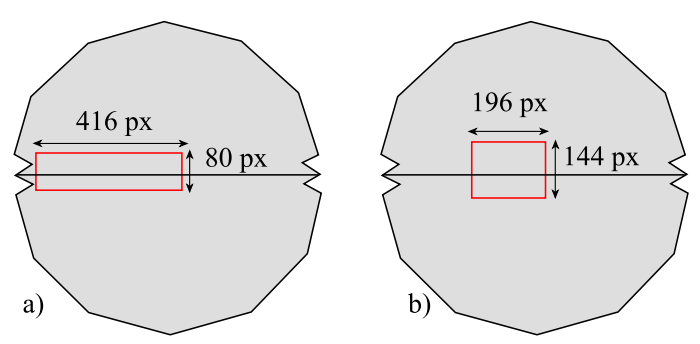

Fig. 11 a) Imaging area for $15^{\circ}$ and $45^{\circ}$ loading conditions. b) Imaging area for the $75^{\circ}$ loading condition

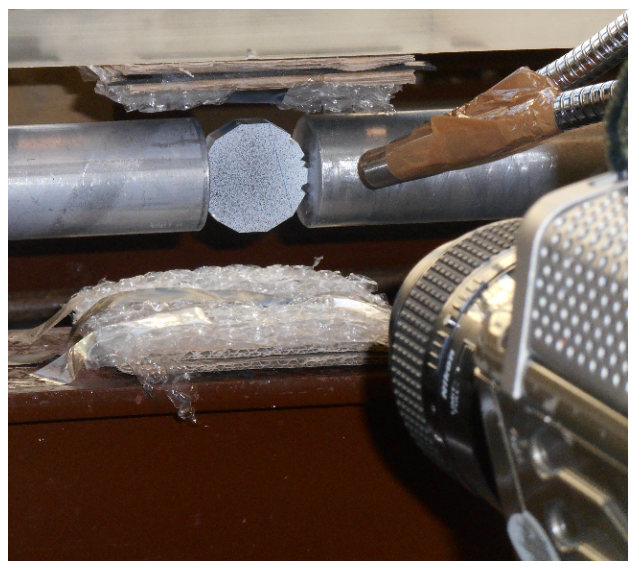

Fig. 12 Photograph of the experimental set-up

specimen face by using a painting adapted to high strain rates. Best results are obtained by applying first a homogenous white coat and then, a black speckle pattern whose typical size is $150 \mu \mathrm{m}$. Speckle size is determined with a digital microscope.

Technical information is summarized in Tab. 2. Images are processed with Vic2D using $9 \times 9$ pixel subset for measuring displacements. This size was chosen to obtain reasonable displacement resolution in substrate areas. Too big subsets propagate high displacements from the adhesive joint to substrates. For measuring strains, bigger subsets $(21 \times 21$ pixel subset $)$ are used because of higher noise present in the strain field. The imaging area is presented in Fig. 11. For $15^{\circ}$ and $45^{\circ}$ loading conditions, the imaging area is initially shifted from the joint plane of 10 pixels in order to take into account the rigid body motion of the specimen during the SHPB test. For the $75^{\circ}$ loading condition, the rigid body motion is more significant and the imaging zone is changed to focus only on the central zone of the specimen. In addition, the imaging area is initially shifted from the joint plane of 30 pixels. A picture of the experimental setup is proposed in Fig. 12 with the camera, the painted specimen, the Hopkinson bar system and a plexiglass protection. A flexible additional lighting system is required to calibrate the imaging area before the test precisely.

Considering the pixel size $(52 \mu \mathrm{m}$ or $55 \mu \mathrm{m})$ and the joint thickness $(300 \mu \mathrm{m})$, this experimental setup does not enable us to measure local displacements in the adhesive joint directly. However, displacement fields in the adherents surrounding the joint are measured accurately. Therefore, a global strain (homogeneous along the joint thickness) can be estimated on this basis. 
Table 3 Summary of four tests for the $45^{\circ}$ loading condition

\begin{tabular}{lll}
\hline $\begin{array}{l}\text { Striker length } \\
(\mathrm{cm})\end{array}$ & $\begin{array}{l}\text { Striker speed } V \\
(\mathrm{~m} / \mathrm{s})\end{array}$ & $\begin{array}{l}\text { Normalized } \\
\text { strength }\end{array}$ \\
\hline 86 & 7.2 & 0.94 \\
86 & 6.3 & 0.89 \\
86 & 5.8 & 0.90 \\
86 & 5.8 & 0.895 \\
\hline
\end{tabular}

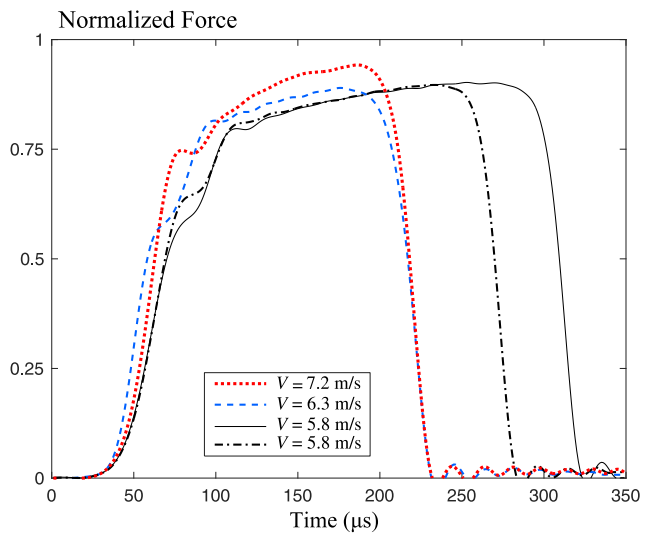

Fig. 13 Normalized force as a function of time for the $45^{\circ}$ loading condition

Table 4 Summary of three tests for the $75^{\circ}$ loading condition

\begin{tabular}{lll}
\hline $\begin{array}{l}\text { Striker length } \\
(\mathrm{cm})\end{array}$ & $\begin{array}{l}\text { Striker speed } V \\
(\mathrm{~m} / \mathrm{s})\end{array}$ & $\begin{array}{l}\text { Normalized } \\
\text { strength }\end{array}$ \\
\hline 120 & 12.4 & 1.6 \\
120 & 11.9 & 1.37 \\
86 & 14.2 & 1.44 \\
\hline
\end{tabular}

Table 5 Summary of three tests for the $15^{\circ}$ loading condition

\begin{tabular}{lll}
\hline $\begin{array}{l}\text { Striker length } \\
(\mathrm{cm})\end{array}$ & $\begin{array}{l}\text { Striker speed } V \\
(\mathrm{~m} / \mathrm{s})\end{array}$ & $\begin{array}{l}\text { Normalized } \\
\text { strength }\end{array}$ \\
\hline 86 & 5.0 & 0.65 \\
86 & 4.3 & 0.56 \\
86 & 4.8 & 0.56 \\
\hline
\end{tabular}

\section{Results and discussion}

This paper focuses on developing a methodology to characterize adhesive joints under dynamic and multiaxial loading conditions. Thus, following experimental results are presented to demonstrate potentialities offered by the proposed methodology but do not aim at contributing to material data bases. Due to confidentiality, most scales are normalized by arbitrary values in the following.

\section{Global measurements}

In this section, typical results obtained with the Hopkinson bar system are presented. Several tests have been performed for each loading condition. The (normalized) force obtained at the specimen/output bar interface is presented as a function of time for the three loading conditions in Fig. 13, 14 and 15. Parameters for different tests and loading conditions are summarized in Tab. 3, 4 and 5. Obtained signals are very similar for each loading condition. Differences are mainly due to variability of the striker speed. The higher the striker speed is and the sharper the output force evolves and the shorter the test is. Indeed, the test duration is limited by the joint failure, because otherwise, the striker length determines the test duration completely. Most presented tests have been performed with a $86 \mathrm{~cm}$ long striker which corresponds to a $350 \mu$ s test. In Fig. 13, 14 and 15, failure is reached before this global value and force drop corresponds to joint failure. In addition, contact conditions, specimen/bar alignment and specimen geometrical (e.g, joint thickness) and material variability explain, to a lesser extent, discrepancies that can be observed in Fig. 13, 14 and 15. Strain rates are evaluated from the Hopkinson tests between 700 and 1500 $\mathrm{s}^{-1}$ depending on the striker speed. 


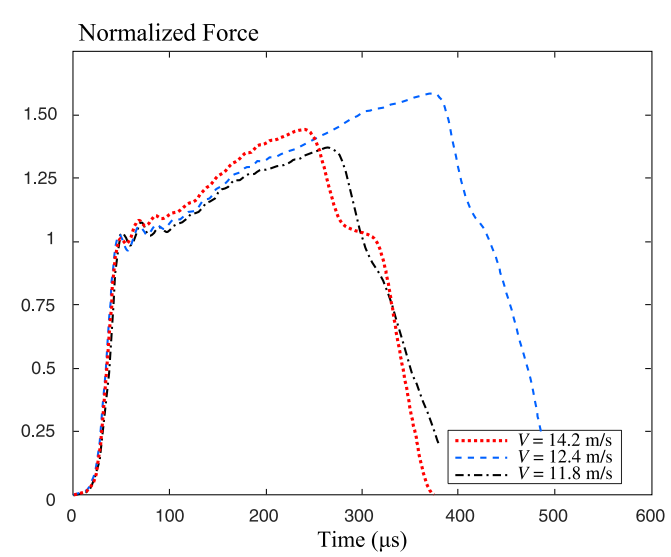

Fig. 14 Normalized force as a function of time for the $75^{\circ}$ loading condition

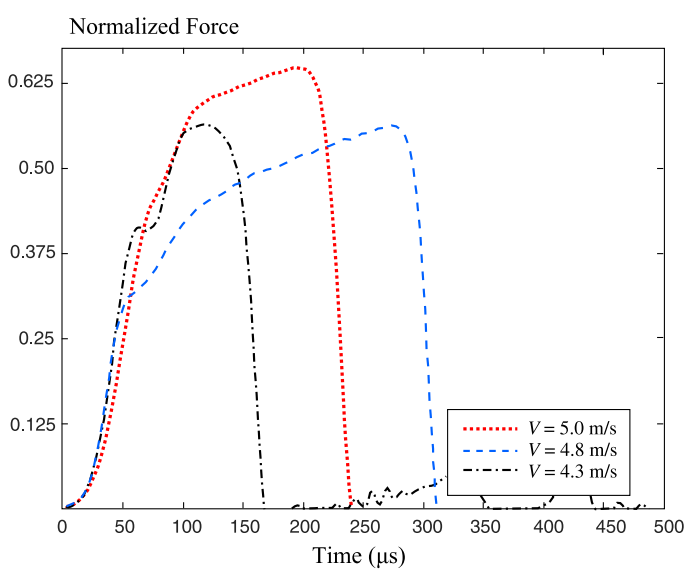

Fig. 15 Normalized force as a function of time for the $15^{\circ}$ loading condition

The assembly strength (maximal force) is very repeatable with a standard deviation evaluated to 2.6 $\%$ of the average normalized strength for the $45^{\circ}$ loading condition. The two other angles show similar standard deviations values concerning assembly strength. The $15^{\circ}$ loading leads to the lowest strength because of the mixed traction/shear stress state. The $75^{\circ}$ loading leads to the highest strength because of the high compression present in the stress state. This global measurement characterizes the whole assembly : adherents and adhesive joint. A local measurement is required to characterize the adhesive joint.

\section{Local measurements}

Striker speeds have been chosen so that 15 to 20 images can be taken during the test before joint failure. Images acquisition is triggered on signal detection at the input strain gauge. Horizontal displacements denoted by $u$ are presented in Fig. 16 for the $45^{\circ}$ loading condition and $V=5.8 \mathrm{~m} / \mathrm{s}$ at different times: $1 \mu \mathrm{s}$, $14 \mu \mathrm{s}, 41 \mu \mathrm{s}$ and $180 \mu \mathrm{s}$. White squares are used as virtual gauges and indicate the specimen center just above and underneath the joint. Displacement amplitude clearly increases with time. Displacement jump between the two adherents is related to the global shear strain in the adhesive joint. Displacements are qualitatively consistent with numerical simulations presented in Fig. 7, shear stress reaches a maximum at the center and decreases near the specimen edges. On the last displacement field at $180 \mu$ s, one can notice zones where the DIC did not work (gray zones along the joint) because deformations were sufficient to make the paint chip off.

Vertical displacements denoted by $v$ are presented in Fig. 16 for the $45^{\circ}$ loading condition and $V=5.8$ $\mathrm{m} / \mathrm{s}$ at $180 \mu \mathrm{s}$. This displacement field is more difficult to interpret because there is no significant displacement jump (extrema lies between 353 and $320 \mu \mathrm{m}$ ). However, accuracy is sufficient to observe the compression level evolution along the joint length qualitatively. At the center (white squares), it is characterized by the difference between blue and green zones which result is low compression level. Compression increases toward the edge until it reaches a maximum characterized by the difference between blue/green 


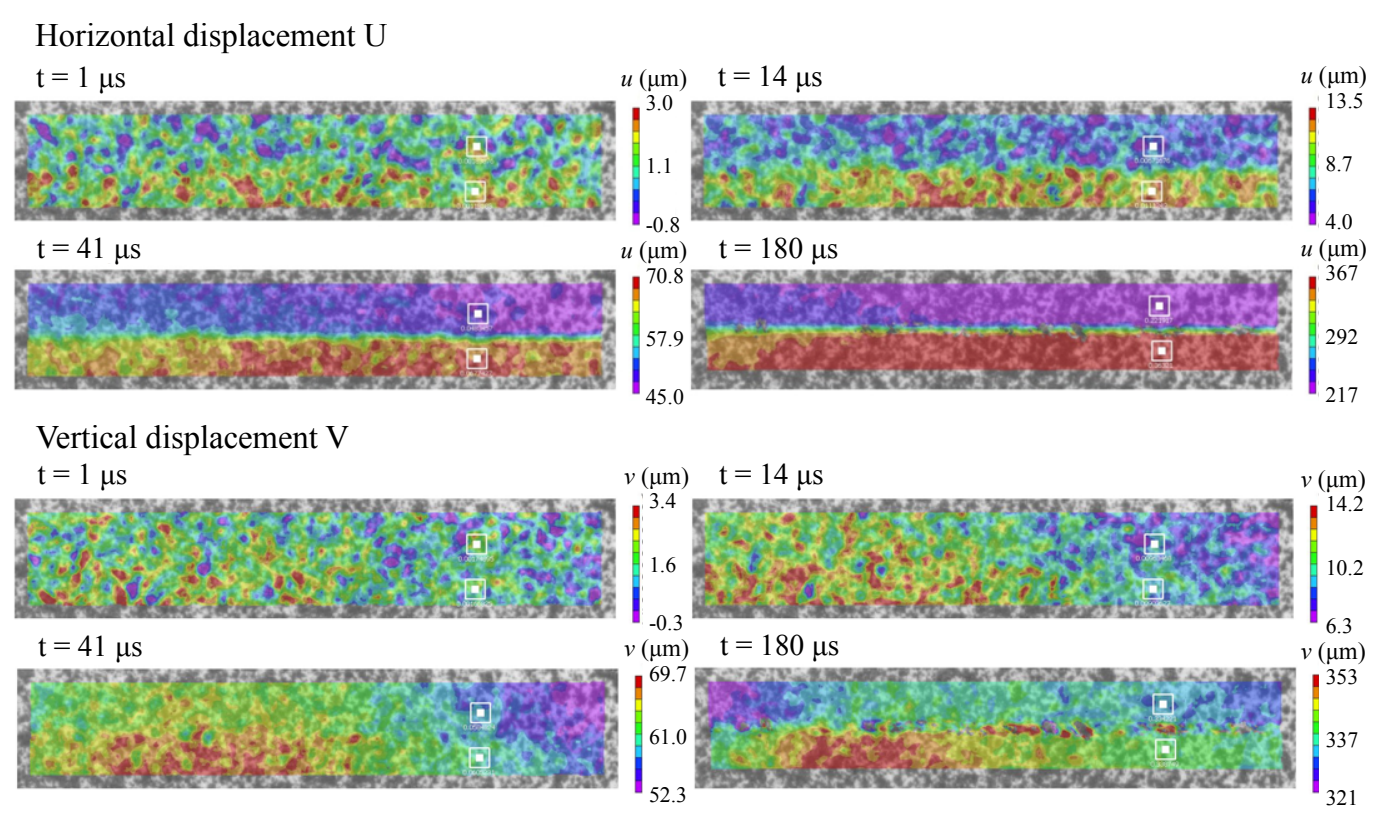

Fig. 16 Horizontal (top) and vertical (bottom) displacement field measured by DIC for the $45^{\circ}$ loading condition at $v=5.8$ $\mathrm{m} / \mathrm{s}$ at different times: $1 \mu \mathrm{s}, 14 \mu \mathrm{s}, 41 \mu \mathrm{s}$ and $180 \mu \mathrm{s}$

and red zones and it decreases at the very edge. This qualitative evolution is consistent with numerical simulations presented in Fig. 7.

Consider $(x, y, z)$ Cartesian coordinates corresponding respectively to the joint length, the joint thickness and the joint depth directions. Strains are computed as the symmetric part of the displacement gradient. Strain fields could be obtained directly from the DIC by considering the numerical gradient of displacements. However, measurement noise is amplified by this numerical procedure. In this contribution, a simplified analysis enables us to overcome this difficulty. Since only surface measurements are available, it is assumed that displacements are homogeneous along the $z$-direction. Thus, displacements along $x$ and $y$ denoted by $u^{*}$ and $v^{*}$ depends only on $x$ and $y$ in the specimen and displacements along $z$ are set to zero. (The superscript * indicates that the quantity is related to the adherent, otherwise the quantity is considered in the adhesive joint). Moreover, as already mentioned, the spatial resolution is not sufficient to measure displacements in the joint directly. Thus, strains in the joint are assumed to be independent on the $y$-direction and are only related to the following displacement variations (where $h$ denotes the joint thickness):

$$
\left\{\begin{array}{l}
\Delta u(x)=u^{*}(x, h / 2)-u^{*}(x,-h / 2) \\
\Delta v(x)=v^{*}(x, h / 2)-v^{*}(x,-h / 2)
\end{array}\right.
$$

And then, displacements $u$ and $v$ in the joint are assumed to be linear as a function of $y$ and reads:

$$
u(x)=\frac{\Delta u(x)}{h} y+f_{u}(x) \text { and } v(x)=\frac{\Delta v(x)}{h} y+f_{v}(x)
$$

Functions $f_{u}(x)$ and $f_{v}(x)$ may be evaluated in Fig. 16. Since strains are evaluated in this study at the joint center (i.e., using displacements in virtual gauges in Fig. 16), $f_{u}(x)$ and $f_{v}(x)$ are neglected. Moreover, variations of $h \Delta v(x)$ along the $x$-directions are assumed to be negligible compared to $\Delta u(x)$, more precisely:

$$
\Delta u(x)>>h \frac{\partial \Delta v(x)}{\partial x}
$$

Thus, by combining (1) and (2), the strain tensor that should be identified along the joint length reads:

$$
\varepsilon_{x y}(x)=\frac{\Delta u(x)}{2 h} \text { and } \varepsilon_{y y}(x)=\frac{\Delta v(x)}{h}
$$

Normalized shear and normal strains are presented as a function of time at the joint center in Fig. 17 and 18 for $15^{\circ}, 45^{\circ}$ and $75^{\circ}$ loading conditions and for $V=5.0, V=5.8, V=14.2 \mathrm{~m} / \mathrm{s}$, respectively. Those time evolutions are consistent with the previous numerical analysis and the three expected stress states described in Tab. 1. Virtual gauges (15-pixel white squares) can solve 1- $\mu$ m displacements which set the minimal strain detection to $5 \cdot 10^{-3}$. 


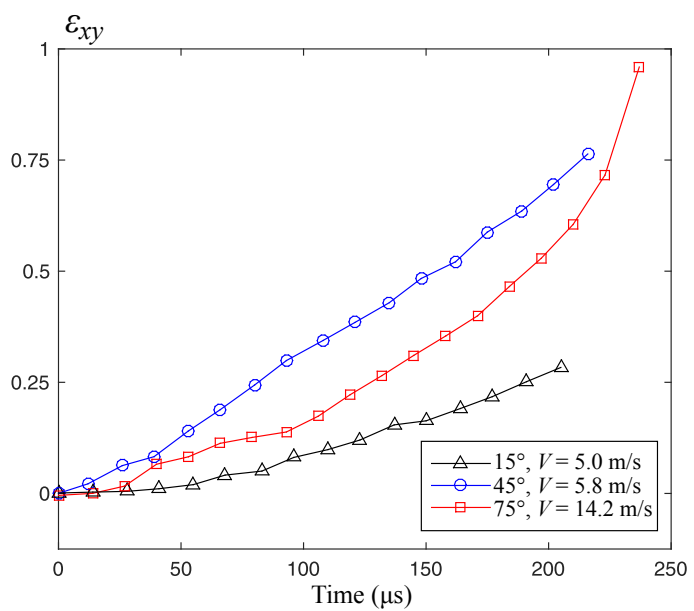

Fig. 17 Normalized shear strain $\varepsilon_{x y}$ as a function of time for $15^{\circ}, 45^{\circ}$ and $75^{\circ}$ loading conditions

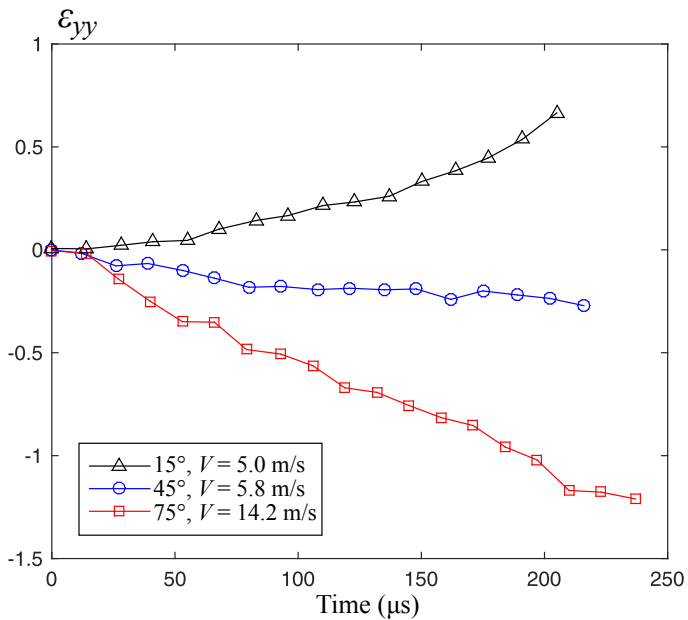

Fig. 18 Normalized normal strain $\varepsilon_{y y}$ as a function of time for $15^{\circ}, 45^{\circ}$ and $75^{\circ}$ loading conditions

Table 6 Summary of normalized failure strain for all tested specimens

\begin{tabular}{lll}
\hline $\begin{array}{l}\text { Loading } \\
\text { condition }\end{array}$ & $\begin{array}{l}\text { Shear } \\
\text { strain at failure }\end{array}$ & $\begin{array}{l}\text { Traction/compression } \\
\text { strain at failure }\end{array}$ \\
\hline $15^{\circ}$ & 0.27 & 0.70 \\
$15^{\circ}$ & 0.13 & 0.25 \\
$15^{\circ}$ & 0.20 & 0.35 \\
\hline $45^{\circ}$ & 0.80 & -0.15 \\
$45^{\circ}$ & 0.75 & -0.25 \\
$45^{\circ}$ & 0.78 & -0.20 \\
$45^{\circ}$ & 0.87 & -0.15 \\
\hline $75^{\circ}$ & 0.98 & -1.30 \\
$75^{\circ}$ & 0.91 & -1.10 \\
$75^{\circ}$ & 0.95 & -1.20 \\
\hline
\end{tabular}

Normalized strains at failure are listed for all tests in Tab. 6. For each loading condition, a good repeatability is observed. In addition, both $45^{\circ}$ and $75^{\circ}$ loading conditions present similar shear strain at failure. The discrepancy may be explained by different compressive strain at failure. Indeed, compressive strain seems to reduce the effectiveness of shear on crack propagation. Much lower shear strains at failure are observed for the $15^{\circ}$ loading condition. This happens because tension is also applied and then mixed shear/traction crack propagation occur.

\section{Local stress measurement and joint behavior}

Even though the measured force at the specimen/output bar interface gives information only about the whole assembly, one can present the global force against the local shear strain measured with DIC. Thus, an approximate behavior of the joint is obtained and presented in Fig. 19. Good reproducibility 


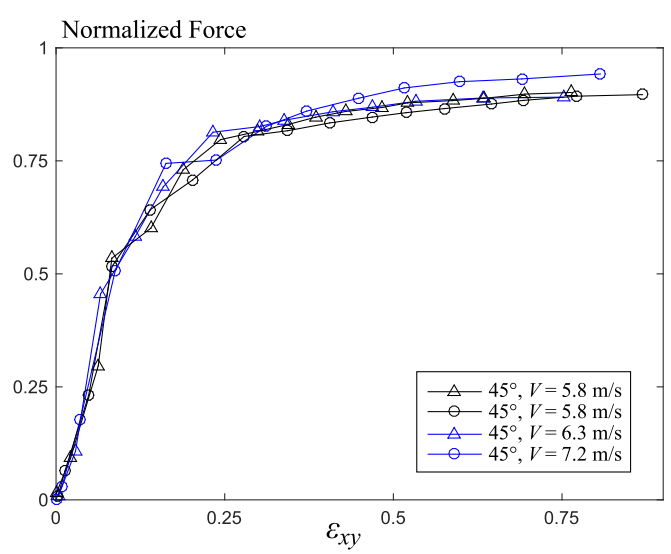

Fig. 19 Normalized force as a function of normalized shear strain $\varepsilon_{x y}$ for $45^{\circ}$ loading conditions

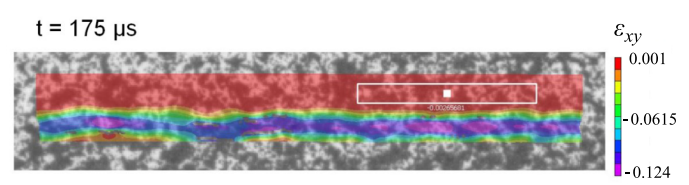

Fig. 20 Shear strain field obtained by DIC for the $45^{\circ}$ loading condition at $175 \mu \mathrm{s}$

Table 7 Identification of normalized elasto-plastic parameters from Fig 21

\begin{tabular}{lll}
\hline & $15^{\circ}$ & $45^{\circ}$ \\
\hline$G$ & 5.9 & 6.2 \\
$\sigma_{y}$ & 0.35 & 0.60 \\
\hline
\end{tabular}

is achieved. This analysis supposes a homogeneous shear stress state all along the joint which is unrealistic from Fig. 7.

Proper behavior of the joint can be derived from the proposed measurements. Local stress measurement in the joint can be performed and inferred directly from the DIC measurement. Thus, the adhesive joint behavior is estimated without the development of an inverse numerical method. Indeed, displacement fields can be post-treated by Vic2D to compute strain fields. As already mentioned, this procedure amplifies measurement noise. However, uncertainties related to the numerical derivation can be reduced by increasing the subset size in the correlation. Thus, strain measurements are obtained in the aluminum adherents near the adhesive joint as shown in Fig. 20 for instance. The virtual gauge (white rectangle) is set to $100 \times 15$ pixels to measure local stresses in the center. The virtual gauge size has been also increased to reduce measurement noise due to numerical derivation. Several assumptions are needed to infer stresses from measured strains. Since surface measurements are done, plane stress state is assumed. Dynamic characterization of the aluminum adherent alone enabled us to identify material parameters (i.e., the Young modulus $E^{*}$, the shear modulus $G^{*}$ and the Poisson ratio $\left.v^{*}\right)$. Elastic behavior is assumed in the aluminum. Stresses in the aluminum adherent are given as a function of strains:

$$
\sigma_{y y}=\frac{E^{*}}{1-\left(v^{*}\right)^{2}}\left(\varepsilon_{y y}+v^{*} \varepsilon_{x x}\right) \text { and } \sigma_{x y}=2 G^{*} \varepsilon_{x y}
$$

Thus, one can measure stresses in the aluminum close to the adherent/joint boundary and infer stresses in the joint by continuity of normal stress (i.e., $\sigma_{y y}$ and $\sigma_{x y}$ ) through the interface. However, the stress component $\sigma_{y y}$ is very difficult to measure in the aluminum adherent because $\varepsilon_{x x}$ and $\varepsilon_{y y}$ are needed and measurement noise of each signal accumulates. In addition, $\varepsilon_{y y}$ is very noisy because there is very few pixels along the $y$-direction. In this contribution, this stress component is not proposed.

Shear strain $\varepsilon_{x y}$ in the adherent is presented in Fig. 20 for the $45^{\circ}$ loading condition at $175 \mu$ s. The red part corresponds to the strain in the adherent and the highly deformed purple part corresponds to the strain in the joint. However, strains in the adhesive part cannot be used because there are too few pixels in the adhesive part. Strains in this part cannot be trusted.

Shear stress in the virtual gauge is then obtained from (5). Stresses are assumed to be homogeneous in the joint along the joint thickness ( $y$-direction). By relating this stress measurement and the strain measurement detailed in section Local measurements, an experimental behavior estimation of the joint can be derived. Normalized results are presented in Fig 21 for $15^{\circ}$ and $45^{\circ}$ loading conditions. Results are not presented for the $75^{\circ}$ as aluminum becomes plastic during this test. Elasto-plastic parameters 


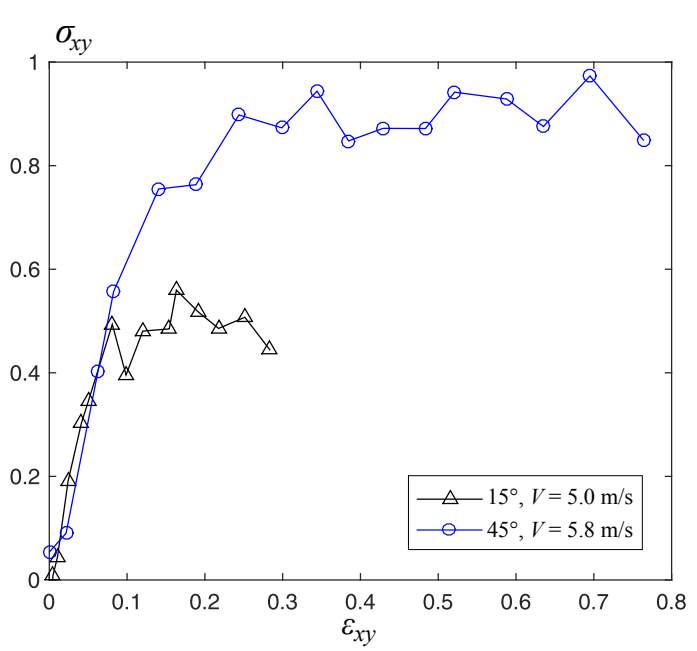

Fig. 21 Adhesive joint behavior identified on $15^{\circ}$ and $45^{\circ}$ loading conditions : normalized shear stress $\sigma_{x y}$ as a function of normalized shear strain $\varepsilon_{x y}$

of the joint can be estimated from the Fig 21. They are shown in Tab 7. As expected, both $15^{\circ}$ and $45^{\circ}$ loading conditions exhibit the same adhesive shear modulus, but different yield and failure stresses. This is a well-known phenomenon for polymers : yield and failure stresses increases with hydrostatic pressure. Thus, $45^{\circ}$-yield stress is higher than $15^{\circ}$-yield stress because of the compression in the test at $45^{\circ}$.

\section{Conclusion}

This paper deals with the development of a new specimen dedicated to dynamic and multiaxial testing of adhesive joints. The general method consists in using classic split Hopkinson pressure bar combined with local displacement measurements performed by Digital Image Correlation. The innovative DODECA specimen allows three different impact loadings, which means three different stress states to test. Simple assumptions on the local displacement field enabled us to get local strain and stress in the adhesive joint and to obtain an experimental estimation of the joint behavior. In addition, strains at failure are also an interesting result of the proposed experimental procedure.

The introduction of DIC in the dynamic characterization of adhesive joints provide new means for developing new adhesive joints testing experiments. This is particularly interesting because of the nonuniformity of the strain field in specimen designed for adhesive joints testing. It will contribute to a further understanding of the material response of adhesive joints.

Further work is still necessary to interpret the presented measurements. In particular, numerical inverse method would be useful to identify a complete behavior of the adhesive joint by minimization procedures. The inverse calculation would require an accurate numerical dynamic model able to represent both force and local displacements with a reasonable calculation time.

Acknowledgements Authors thank Philippe Chevallier (LMS) for his help with experiments and Gerard Gary (LMS) for his useful advice on dynamic experiments.

\section{References}

1. Cognard JY, Créac'hcadec R, Sohier L, Davies P (2008) Analysis of the nonlinear behavior of adhesives in bonded assemblies-comparison of tast and arcan tests. International Journal of Adhesion and Adhesives 28(8):393-404

2. Carrere N, Badulescu C, Cognard JY, Leguillon D (2015) 3d models of specimens with a scarf joint to test the adhesive and cohesive multi-axial behavior of adhesives. International Journal of Adhesion and Adhesives 62:154-164

3. Adamvalli M, Parameswaran V (2008) Dynamic strength of adhesive single lap joints at high temperature. International Journal of Adhesion and Adhesives 28(6):321-327

4. Challita G, Othman R (2010) Finite-element analysis of SHPB tests on double-lap adhesive joints. International Journal of Adhesion and Adhesives 30(4):236-244 
5. Challita G, Othman R, Casari P, Khalil K (2011) Experimental investigation of the shear dynamic behavior of double-lap adhesively bonded joints on a wide range of strain rates. International Journal of Adhesion and Adhesives 31(3):146-153

6. Halary JL, Lauprêtre F (2015) Mécanique des matériaux polymères. Belin

7. Raykhere SL, Kumar P, Singh R, Parameswaran V (2010) Dynamic shear strength of adhesive joints made of metallic and composite adherents. Materials \& Design 31(4):2102-2109

8. Roth CC, Gary G, Mohr D (2015) Compact SHPB system for intermediate and high strain rate plasticity and fracture testing of sheet metal. Experimental mechanics 55:1803-1811

9. Rittel D, Maigre H (1996) An investigation of dynamic crack initiation in PMMA. Mechanics of Materials 23(3):229-239

10. Zhao J, Knauss W, Ravichandran G (2009) A new shear-compression-specimen for determining quasistatic and dynamic polymer properties. Experimental mechanics 49(3):427

11. Dorogoy A, Rittel D, Godinger A (2016) A shear-tension specimen for large strain testing. Experimental Mechanics 56(3):437-449

12. Kuhn P, Catalanotti G, Xavier J, Camanho P, Koerber H (2017) Fracture toughness and crack resistance curves for fiber compressive failure mode in polymer composites under high rate loading. Composite Structures 182:164-175

13. Zhou J, Wang Y, Xia Y (2006) Mode-I fracture toughness of PMMA at high loading rates. Journal of materials science 41(24):8363-8366

14. Wang Q, Feng F, Ni M, Gou X (2011) Measurement of mode I and mode II rock dynamic fracture toughness with cracked straight through flattened Brazilian disc impacted by split Hopkinson pressure bar. Engineering Fracture Mechanics 78(12):2455-2469

15. Banks-Sills L, Schwartz J (2002) Fracture testing of Brazilian disk sandwich specimens. International journal of fracture 118(3):191-209

16. Martin E, Pavia F, Ventrella A, Avalle M, Lara-Curzio E, Ferraris M (2012) A Brazilian disk test for the evaluation of the shear strength of epoxy-joined ceramics. International Journal of Applied Ceramic Technology 9(4):808-815

17. Janin A, Constantinescu A, Weisz-Patrault D, Neviere R, Stackler M, Albouy W (2017) An experimental technique for the characterization of adhesive joints under dynamic multiaxial loadings. Procedia Engineering 197:52-59

18. Thevamaran R, Daraio C (2014) An experimental technique for the dynamic characterization of soft complex materials. Experimental Mechanics 54(8):1319-1328

19. Zhang Q, Zhao J (2014) Quasi-static and dynamic fracture behaviour of rock materials: phenomena and mechanisms. International Journal of Fracture 189(1):1-32

20. Hild F, Roux S (2006) Digital image correlation: from displacement measurement to identification of elastic properties-a review. Strain 42(2):69-80

21. Roux S, Hild F (2006) Stress intensity factor measurements from digital image correlation: postprocessing and integrated approaches. International journal of fracture 140(1):141-157

22. Gilat A, Schmidt T, Walker A (2009) Full field strain measurement in compression and tensile split Hopkinson bar experiments. Experimental Mechanics 49(2):291-302

23. Koerber H, Xavier J, Camanho P (2010) High strain rate characterisation of unidirectional carbonepoxy IM7-8552 in transverse compression and in-plane shear using digital image correlation. Mechanics of Materials 42(11):1004-1019

24. Seidt J, Kuokkala V, Smith J, Gilat A (2016) Synchronous full-field strain and temperature measurement in tensile tests at low, intermediate and high strain rates. Experimental Mechanics 2(57):219229

25. Reu P (2014) All about speckles: aliasing. Experimental Techniques 38(5):1-3

26. Kolsky H (1949) An investigation of the mechanical properties of materials at very high rates of loading. Proceedings of the Physical Society Section B 62(11):676

27. Gary G (2001) Comportement des métaux à grande vitesse de déformation. Modélisation. Ed. Techniques Ingénieur

28. Jiang F, Vecchio KS (2009) Hopkinson bar loaded fracture experimental technique: a critical review of dynamic fracture toughness tests. Applied Mechanics Reviews 62(6):060,802

29. Chen WW, Song B (2010) Split Hopkinson (Kolsky) bar: design, testing and applications. Springer Science \& Business Media

30. Gary G (2005) DAVID instruction manual. LMS, Palaiseau, France

31. Safa K, Gary G (2010) Displacement correction for punching at a dynamically loaded bar end. International Journal of Impact Engineering 37(4):371-384

32. Abaqus UM (2006) Abaqus

33. Cognard JY, Créachcadec R, Sohier L, Leguillon D (2010) Influence of adhesive thickness on the behaviour of bonded assemblies under shear loadings using a modified TAST fixture. International 
Journal of Adhesion and Adhesives 30(5):257-266

34. Leguillon D, Sanchez-Palencia E (1987) Computation of singular solutions in elliptic problems and elasticity. John Wiley \& Sons, Inc. 